\title{
Futurisme et Surréalisme, études réunies par François
} Livi

\section{Gian Luigi Di Bernardini}

\section{(2) OpenEdition}

1 Journals

\section{Edizione digitale}

URL: http://journals.openedition.org/studifrancesi/7009

DOI: $10.4000 /$ studifrancesi.7009

ISSN: 2421-5856

\section{Editore}

Rosenberg \& Sellier

\section{Edizione cartacea}

Data di pubblicazione: 1 septembre 2010

Paginazione: 401

ISSN: 0039-2944

\section{Notizia bibliografica digitale}

Gian Luigi Di Bernardini, «Futurisme et Surréalisme, études réunies par François Livi», Studi Francesi [Online], 161 (LIV | II) | 2010, online dal 30 novembre 2015, consultato il 13 janvier 2021. URL: http:// journals.openedition.org/studifrancesi/7009 ; DOI: https://doi.org/10.4000/studifrancesi.7009

Questo documento è stato generato automaticamente il 13 janvier 2021.

\section{(c) (i) (9)}

Studi Francesi è distribuita con Licenza Creative Commons Attribuzione - Non commerciale - Non opere derivate 4.0 Internazionale. 


\title{
Futurisme et Surréalisme, études réunies par François Livi
}

\author{
Gian Luigi Di Bernardini
}

\section{NOTIZIA}

Futurisme et Surréalisme, études réunies par François Livi avec le concours de Silvia CONTARINI, Karine MARTIN-CARDINI, Catherine LANFRANCHI, Lausanne, L'Âge d'Homme, 2008, pp. 316.

1 Questo volume raccoglie gli atti dell'omonimo convegno, tenutosi il 13 e 14 aprile 2002 all'Università di Nantes, che costituiva la prima tappa di un più ampio percorso di ricerca teso a definire il ruolo del Futurismo nell'ambito dell'elaborazione dei movimenti d'avanguardia all'inizio del xx secolo. Gli interventi qui raccolti concentrano prioritariamente l'attenzione sui rapporti intercorsi tra Futurismo e Surrealismo evitando, però, di inglobare i due movimenti in un'indistinta avanguardia storica e mantenendo opportunamente distinte le rispettive specificità identitarie.

Il volume è suddiviso in tre ampie sezioni. La prima, dal titolo «Intersections», ospita alcuni pregevoli interventi. Tra di essi ci sembra particolarmente opportuno segnalare il primo, dal titolo Apostilles aux "Manifestes du Futurisme" sur les fonctions du langage di Gérard GENOT (pp. 21-34), che offre un'analisi linguistica approfondita e rigorosa dei manifesti futuristi.

3 La seconda sezione, dal titolo «Figures et problèmes», raccoglie interventi di natura eterogenea concernenti per lo più figure marginali del Futurismo e del Surrealismo come la scrittrice Paola Masino (Fulvia AIROLDI NAMER, L'Improbable surréalisme de Paola Masino, pp. 165-182) o di Gallian (Paul colombanI, Marcello Gallian entre Futurisme et Surréalisme ou plutôt du squadrisme comme idéologie, pp. 209-221). Vorremmo segnalare, in particolare, almeno la bella analisi poetico-estetica del Manifesto della radio di Marinetti e Masnara del 1933 (Antonio SACCONE, Le Futurisme et le langage radiophonique, pp. 
183-194) e il lavoro sulla rivista «Stile futurista» e la figura del teorico Fillìa (Serge MILAN, Fillia, ou du Futurisme en tant que style, pp. 197-207).

4 La terza sezione, «Dialogues», indaga, come suggerisce il titolo stesso, sulle relazioni tra i due movimenti d'avanguardia dei diversi paesi europei: l'analisi non investe solamente il più evidente caso dei rapporti franco-italiani, ma esplora anche percorsi meno battuti come il rapporto tra Italia e Germania (Nicolas SURPIERRE, Un écart métaphysique: la part italienne du réalisme magique allemand, pp. 237-252), oppure la presenza dell'avanguardia in Galizia (Loïc FRAVALO, L'Avant-garde du nord-ouest ibérique, pp. 253-266). 